Review Article

\title{
Fluticasone propionate/formoterol: A fixed-combination therapy with flexible dosage
}

\author{
A. Papi ${ }^{\text {a,* }}$, F. Blasi ${ }^{\text {b,** }}{ }^{*}$, G.W. Canonica ${ }^{\text {c }}$, M. Cazzola ${ }^{\text {d }}$, S. Centanni ${ }^{\text {e }}$, M.P. Foschino Barbaro ${ }^{\mathrm{f}}$, A.S. Melani ${ }^{\mathrm{g}}$, \\ P. Paggiaro ${ }^{\mathrm{h}}$, F. Ricciardolo $^{\mathrm{i}}$, A. Rossi $^{\mathrm{j}}$, N. Scichilone $^{\mathrm{k}}$
}

a Head Respiratory Medicine and Research Centre on Asthma and COPD, University of Ferrara, Ferrara, Italy

b Department of Pathophysiology and Transplantation, University of Milan, IRCCS Fondazione Cà Granda, Milano, Italy

c Allergy and Respiratory Disease Clinic, University of Genova, Genova, Italy

d Unit of Respiratory Clinical Pharmacology, Department of System Medicine, University of Rome Tor Vergata, Roma, Italy

e Respiratory Unit, San Paolo Hospital, Dipartimento di Scienze della Salute, Università degli Studi di Milano, Milan, Italy

${ }^{\mathrm{f}}$ Department of Medical and Surgical Sciences University of Foggia, Foggia, Italy

${ }^{g}$ Respiratory Pathophysiology, Cardiothoracic Dept., University Hospital, Siena, Italy

${ }^{\mathrm{h}}$ Respiratory Pathophysiology and Rehabilitation Unit, Cardio-Thoracic and Vascular Department, University of Pisa, Pisa, Italy

${ }^{i}$ Department of Clinical and Biological Sciences, University of Torino, Torino, Italy

j Pulmonary Unit, Department of Medicine, University of Verona, Verona, Italy

${ }^{\mathrm{k}}$ Department of Medicine, Section of Pulmunology, University of Palermo, Palermo, Italy

\section{A R T I C L E I N F O}

\section{Article history:}

Received 26 March 2014

Received in revised form 21 June 2014

Accepted 24 June 2014

Available online 19 July 2014

\section{Keywords:}

Asthma control

Asthma exacerbations

Fluticasone propionate/formoterol

Fixed-combination therapy

Single-aerosol inhaler

\begin{abstract}
A B S T R A C T
International guidelines describe asthma control as the main outcome of asthma management. Prevention of symptoms, improved quality of life, and reduction of exacerbations are the main components, consequently decreasing health care costs. However, many of these objectives remain unmet in real life: several surveys show that a large proportion of asthmatic patients are not well controlled despite the efficacy of current available treatment. Several randomized controlled clinical trials indicate that combining inhaled corticosteroids and long-acting $\beta_{2}-$ agonists, by means of a single inhaler, greatly improves the management of the disease. The results of 9 multicenter phase III clinical studies demonstrate that the fixed combination of fluticasone propionate/formoterol in a single inhaler is effective in terms of lung function and symptom control. These studies highlight the dose flexibility, safety and tolerability of this new inhaled combination. These characteristics meet the recommendations of international guidelines, and the preferences of respiratory physicians who identified these aspects as critical components of a successful asthma therapy. Combination of fluticasone propionate/formoterol in a single inhaler provides potent anti-inflammatory activity of fluticasone propionate and rapid onset of action of the $\beta_{2}$-agonist formoterol making this association a viable treatment option both in terms of effectiveness and compliance.

(c) 2014 European Federation of Internal Medicine. Published by Elsevier B.V. All rights reserved.
\end{abstract}

\section{Introduction}

Asthma affects about 300 million people of all ages and ethnic groups worldwide [1], with an estimated increase in prevalence to 400 million by 2025 [2]. The economic burden in terms of direct (hospitalization, use of emergency room visits, therapy) and indirect (missed days of work/school) costs adds to the emotional, physical and social impact of asthma, with consequent quality of life deterioration for both patients and their families [3]. Despite the availability of effective treatments, a large proportion of asthma patients experience symptoms of uncontrolled asthma, even in those geographical areas where good standards of care are available $[2,4-8]$.

\footnotetext{
* Corresponding author at: Head Respiratory Medicine and Research Center on Asthma and COPD, University of Ferrara, Via Rampari di San Rocco, 27, 44121 Ferrara, Italy. Tel.: + 390532 210420; fax: + 390532210297.

** Corresponding author.

E-mail address: francesco.blasi@unimi.it (F. Blasi).
}

In the AIRE (Asthma Insights and Reality in Europe) study, involving over 2800 patients from different European countries, more than half of the patients reported daytime asthma symptoms and a third complained of asthma-related sleep disturbances [9]. The INSPIRE (International Asthma Patient Insight Research) study, where 3415 adults treated for asthma were interviewed, reported daily use of rescue short-acting bronchodilator in almost $74 \%$ of the patients, while $51 \%$ had experienced at least one exacerbation in the previous year [7]. More recently, in 2006, 2008 and 2010, the results of three surveys in patients from five European countries (France, Germany, Italy, Spain and United Kingdom) revealed that $50 \%$ or more of asthma patients reported suboptimal symptom multi-dose DPIscontrol $[5,10,11]$.

\section{Potential causes of inadequate asthma control}

Among the possible causes of impaired asthma control, the heterogeneity of the disease, the continued exposure to irritants or triggers, 
the presence of co-morbid conditions [12] and the lack of patient adherence to treatment [13] should be considered. In the last years some greater attention has been put in the diagnosis and management of comorbidities and triggers. By contrast, non-adherence to medications remains very common in asthma, perhaps more than in other chronic diseases. Indeed, there is evidence to indicate that a combination of suboptimal use of available drugs, poor adherence to treatment and misjudgment of the level of asthma control by physicians and/or patients, contributes to unsuccessful disease control. Possibly this is also due to poor inhaler technique, a variety of unintentional nonadherence, which is widespread and neglected in asthma [14]. Two main types of inhaler devices are currently available for drug lung delivery in asthma, metered dose inhalers (MDIs) and dry powder inhalers (DPIs). Importantly, the issue of inhaler misuse was firstly recognized with MDIs, as the diffusion of DPIs is relatively recent. However, it is currently known that inhaler misuse is common with both MDIs and DPIs and is associated with poor asthma control with both devices [15]. Although it is increasingly believed that a careful choice of the most appropriate inhaler device, in accordance with the patient, can certainly improve patient's satisfaction, adherence and clinical outcomes, guidelines do not give a clear indication about the best device. In fact, it is accepted that different devices are clinically equivalent with regard to safety and efficacy when they are used to deliver the same drug at equipotent doses [16]. Similarly, there is no clear evidence for a preference between inhaler devices [17]. However, simplifying the regimen schedule, by including the use of a single inhaler with different drug combinations, or using the same type of device when different drugs are required, or the addition of bronchodilators with fast onset of action may improve asthma adherence and control. This may suggest the use of MDIs as first inhaler option in asthma. Moreover, although the price of different asthma inhaler drugs is variable between countries and depends on the agreement between manufacturers and health providers, MDIs are also cheaper than multi-dose DPIs.

Knowledge, belief and behavior of physicians are crucial elements of the management and follow-up of chronic inflammatory disorders, including asthma [18]. A recent survey conducted among general practitioners (GPs, $\mathrm{n}=811$ ) and respiratory medicine specialists $(\mathrm{n}=230)$ investigated physician-related factors potentially contributing to asthma control failures. In this survey physicians considered $40 \%$ of asthma patients might not require continuous therapy, despite acknowledging the role of airway inflammation in the pathogenesis of disease [18]. Similar results were observed in the GAPP (Global Asthma Physician and Patient), study, a survey based on 3559 interviews in 16 countries worldwide among physicians, adult asthma patients and asthma nurses [19].

\section{Goals of asthma management}

The first editions of the Global Initiative for Asthma (GINA) recommendations evaluated asthma severity based on the clinical characteristics of the patients. In the following years it became increasingly evident that the evaluation of asthma severity must involve patient's response to treatment. More recently, the international recommendations suggest assessing the level of asthma control at each current patient's level of treatment. The selection of parameters for asthma control level assessment include daytime and nighttime symptoms, limitations of daily activity, impairment of lung functions, and use of rescue medications. A step-up/step-down approach is recommended to achieve these goals. This includes the dosage increase of controller medications or the introduction of another medication in those patients where asthma is not well controlled. Moreover, in cases of adequate disease control, the reduction of dosage and number of medications is recommended as well, to minimize adverse effects and health care costs [20].

The results of numerous randomized and controlled clinical studies have demonstrated the efficacy of using ICS/LABA (an inhaled corticosteroid combined with a long-acting inhaled $\beta_{2}$-agonist) in a single inhaler for the treatment of asthma of patients not controlled by low doses of inhaled steroids [21-26]. Moreover, it has been shown that the combination of these drugs considerably improved the management of asthma symptoms, including mild and severe exacerbations, as compared with the administration of ICS as monotherapy $[27,28]$.

Recently, a study was performed to evaluate the characteristics of ICS/LABA combination therapy, considered by physicians as more relevant for asthma treatment. GPs and specialists from European countries were asked to complete Delphi questionnaires and to take sequential surveys. At the end of this survey, a panel of experts highlighted six main characteristics of ICS/LABA combination treatment: i) dosage flexibility ( $88 \%$ of attendees), ii) safety and long-term tolerability of ICS (81\%), iii) safety and long-term tolerability of LABA (81\%), iv) efficacy in asthma control (69\%), v) anti-inflammatory power of ICS (69\%), vi) rapid bronchodilator activity of LABA (68\%) [Table 1] [29].

Recently, a new combination ICS/LABA became available in the market, developed with fluticasone propionate and formoterol in three dosages of 50/5 $\mu \mathrm{g}, 125 / 5 \mu \mathrm{g}$ and $250 / 10 \mu \mathrm{g}$, respectively, per actuation.

\section{Fluticasone propionate and formoterol}

International guidelines for the management of asthma recommend the administration of a LABA along with ICS when symptoms are not well controlled using low doses of ICS monotherapy [30,31] [Fig. 1]. Combined treatment with ICS and LABA by a single inhaler has some advantages, in terms of pharmacology and compliance, compared with treatments administered separately. Indeed, it had been demonstrated that concurrent ICS and LABA can pharmacologically synergize. In clinical trials ICS/LABA combination is superior to higher doses ICS on relevant clinical outcomes [6,23,32-35], and that the use of a single inhaler improves patient adherence to therapy and ensures that the LABA is not taken as a single medication without the inhaled steroid $[30,33,36,37]$.

The choice of ICS and LABA to be combined in the same inhaler is crucial because both ICSs and LABAs differ in terms of their specific pharmacological profiles as a result of the different chemical structures of individual agents. In the present review we only discuss ICS and LABA entering a fixed ICS/LABA combination. Fluticasone propionate is one of the most potent ICSs [35]. It has a very low oral bioavailability $(\leq 1 \%)$ [35] and it is well accepted that low oral availability $(<10 \%)$ decreases systemic availability and the incidence of adverse events [38]. High receptor binding strength is correlated with high anti-inflammatory activity [39]. The relative receptor-binding affinity (vs dexamethasone) of fluticasone propionate is second only to mometasone [35]; however, the inhalation half-life of mometasone is much lower than that of fluticasone propionate [35]. Being inhalation half-life a critical property for an ICS as it relates to pulmonary retention time (i.e. the rate at which ICSs are absorbed across the pulmonary membranes and out of the airways) [40]. This is a disadvantage for mometasone because longer pulmonary retention is related to prolonged efficacy [40]. Moreover, fluticasone propionate is the most lipophilically active ICS [35], and therefore has a long duration of anti-inflammatory action. In fact, higher lipophilicity is positively correlated with increased retention in the lung and longer duration of action [38].

Table 1

Expert panel agreement ${ }^{*}$ on the characteristics of an effective ICS/LABA combination therapy. The results refer to the final round of a Delphi process [29].

\begin{tabular}{ll}
\hline Treatment attribute & Percentage of agreement \\
\hline Dosage flexibility & $88 \%$ \\
ICS: long term safety and tolerability & $81 \%$ \\
LABA: long term safety and tolerability & $81 \%$ \\
Efficacy (asthma control) & $81 \%$ \\
ICS: anti-inflammatory effect & $69 \%$ \\
LABA: speed of onset & $69 \%$ \\
\hline
\end{tabular}

ICS, inhaled corticosteroid; LABA, long-acting inhaled $\beta_{2}$-agonist.

$*$ Agreement $=$ consensus in a percentage of experts $\geq 66 \%$ 


\begin{tabular}{|c|c|c|c|c|}
\hline Step 1 & Step 2 & Step 3 & Step 4 & Step 5 \\
\hline \multicolumn{5}{|c|}{$\begin{array}{l}\text { Asthma education. Environmental control. } \\
\text { (If step-up treatment is being considered for poor symptom control, first check inhaler technique, check adherence, and confirm symptoms are due to asthma.) }\end{array}$} \\
\hline $\begin{array}{l}\text { As needed rapid- } \\
\text { acting } \beta_{2} \text {-agonist }\end{array}$ & \multicolumn{4}{|c|}{ As needed rapid-acting $\beta_{2}$-agonist } \\
\hline \multirow{5}{*}{$\begin{array}{l}\text { Controller } \\
\text { options*** }\end{array}$} & Select one & Select one & $\begin{array}{l}\text { To Step } 3 \text { treatment, } \\
\text { select one or more }\end{array}$ & $\begin{array}{l}\text { To Step } 4 \text { treatment, } \\
\text { add either }\end{array}$ \\
\hline & $\begin{array}{l}\text { Low-dose inhaled } \\
\text { ICS* }\end{array}$ & $\begin{array}{l}\text { Low-dose ICS plus } \\
\text { long-acting } \beta_{2} \text {-agonist }\end{array}$ & $\begin{array}{c}\text { Medium-or high-dose } \\
\text { ICS plus long-acting } \\
\beta_{2} \text {-agonist }\end{array}$ & $\begin{array}{l}\text { Oral glucocorticosteroid } \\
\text { (lowest dose) }\end{array}$ \\
\hline & \multirow[t]{2}{*}{$\begin{array}{l}\text { Leukotriene } \\
\text { modifier** }\end{array}$} & $\begin{array}{c}\text { Medium-or } \\
\text { high-dose ICS }\end{array}$ & $\begin{array}{l}\text { Leukotriene } \\
\text { modifier }\end{array}$ & $\begin{array}{l}\text { Anti-lgE } \\
\text { treatment }\end{array}$ \\
\hline & & $\begin{array}{l}\text { Low-dose ICS plus } \\
\text { leukotriene modifier }\end{array}$ & $\begin{array}{l}\text { Sustained release } \\
\text { theophylline }\end{array}$ & \\
\hline & & $\begin{array}{l}\text { Low-dose ICS plus } \\
\text { sustained release } \\
\text { theophylline }\end{array}$ & & \\
\hline
\end{tabular}

* ICS $=$ inhaled glucocorticosteroids

${ }^{* *}=$ Receptor antagonist or synthesis inhibitors

${ }^{* \star *}=$ Recommended treatment (shaded boxes) based on group mean data. Individual patient needs, preferences, and circumstances (including costs) should be considered.

Alternative reliever treatments include inhaled anticholinergics, short-acting oral $\beta_{2}$-agonists, some long-acting $\beta_{2}$-agonists, and short-acting theophylline.

Regular dosing with short and long-acting $\beta_{2}$-agonists is not advised unless accompanied by regular use of an inhaled glucocorticorsteriod.

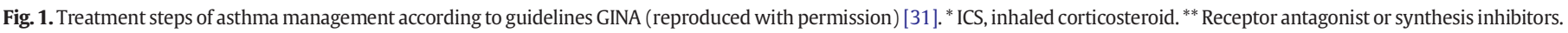
*** Recommended treatment (shaded boxes) based on group mean data. Individual patient needs, preferences, and circumstances (including costs) should be considered.

Pharmacological characteristics that could theoretically optimize ICS effectiveness include a low oral and a high pulmonary bioavailability, high receptor-binding affinity, high protein-binding capacity and a long pulmonary retention time [38]. Important properties for a LABA include speed of onset of action, duration of action and agonist activity at the $\beta_{2}$-adrenoceptor [41]. Formoterol is the fastest acting inhaled LABA, considerably quicker than salmeterol [42]. The duration of bronchodilatory action of formoterol is up to $12 \mathrm{~h}$, longer than that of salbutamol and similar to that of salmeterol [43]. However, the rapid onset of action supports the use of formoterol as a reliever medication in addition to use in maintenance therapy [43].

Pharmacologically, the clearest distinguishing feature between $\beta_{2}$ agonists is the extent to which they activate the receptor, termed intrinsic efficacy [44]. It is a key pharmacologic parameter that differs dramatically among available $\beta_{2}$-agonists [41]. Formoterol demonstrates high intrinsic efficacy when stimulating cyclic adenosine monophosphate (cAMP) generation, whereas salmeterol has a much lower intrinsic efficacy, appearing as a partial agonist in all but the most highly expressed recombinant systems [45]. Actually, in the maintenance setting, salmeterol has a low intrinsic efficacy (i.e., is a weak partial agonist, with intrinsic efficacy less than $2 \%$ relative to adrenaline), whereas formoterol has a relatively high intrinsic efficacy. It can be expected that more severely affected patients with asthma will show greater responses to formoterol, whereas patients having problems with side effects might do better with salmeterol [46]. Unfortunately, the degree of agonistinduced desensitization of the $\beta_{2}$-adrenoceptor also is related to agonist efficacy (strength of signaling), whereby high-efficacy agonists (e.g. formoterol) cause more phosphorylation and internalization of the receptor than low-efficacy agonists (e.g. salmeterol) [47].

However, high-efficacy agonists do not necessarily cause more functional desensitization, as was once believed [44]. It is known that partial agonists are generally more sensitive to the reduction of functional receptors than full agonists $[44,48]$. In fact, low-efficacy ligands are less able to activate the receptor and may not be sufficient to generate a full response, even when bound to all available receptors. In contrast, high-efficacy agonists may only need to occupy a small percentage of receptors to generate a full response, thereby leaving 'spare receptors' [44].

\subsection{Functional benefits of combination therapy}

The results of clinical studies conducted on fluticasone propionate/ formoterol combination treatment demonstrate better efficacy in terms of improvement of respiratory function, compared with the results of the single drugs administered as monotherapy. The contribution of single components in improving respiratory function has been evaluated by assessing 1) the changes from baseline of pre-dose forced expiratory volume in $1 \mathrm{~s}\left(\mathrm{FEV}_{1}\right)$ at week 12 , when comparing fluticasone proprionate/ formoterol versus fluticasone propionate, and 2) FEV1 changes from predose baseline to $2 \mathrm{~h}$ post-dose at week 12 when comparing fluticasone propionate/formoterol versus formoterol [33-35,37,49].

A new once daily fluticasone furoate/vilanterol combination has been recently approved by regulatory agencies for the use in asthma and COPD. It confirms the superiority of ICS plus LABA over monocomponents on relevant outcomes

\subsection{Therapeutic efficacy and tolerability}

The therapeutic efficacy of the fluticasone propionate/formoterol combination has been evaluated in nine multicenter phase III clinical studies [32-34,50-55] on patients aged $\geq 12$ years [32-34,50-55] or aged $\geq 18$ years $[32,33]$ with mild to moderate $[53,54]$, moderate to severe $[32,33,50,51,55]$ or mild to moderate-severe persistent asthma $[34,52]$ [Table 2]. Further studies and pooled analyses are to be expected. The results of the published clinical studies showed that 8-12 week treatment with fluticasone propionate/formoterol combination in a single inhaler, at dosages of $100 / 10 \mu$ b.i.d., $250 / 10 \mu$ b.i.d. and 500/20 $\mu \mathrm{g}$ b.i.d., have shown superior clinical efficacy to the same doses of the single medications. Fluticasone proprionate/formoterol combination is marketed at the following dosages: 50 fluticasone proprionate $/ 5 \mu \mathrm{g}$ formoterol, 125 fluticasone proprionate $/ 5 \mu \mathrm{g}$ formoterol and 250 fluticasone proprionate $/ 10 \mu \mathrm{g}$ formoterol. Two puffs b.i.d. is the recommended regimen. These results were confirmed by a combined data analysis of five randomized double-blind studies, conducted in moderate or moderate-severe asthma patients, treated for 8 weeks or 12 week 
Table 2

Efficacy of the combination fluticasone/formoterol for the treatment of asthma patients: results of phase III clinical studies.

\begin{tabular}{|c|c|c|c|c|c|c|}
\hline Study & Asthma severity & $\begin{array}{l}\text { Patient age } \\
\text { (y) }\end{array}$ & $\begin{array}{l}\text { Treatment } \\
\text { duration } \\
\text { (weeks) }\end{array}$ & Comparative treatment & Primary endpoint & $\begin{array}{l}\text { Result of fluticasone/ } \\
\text { formoterol combination }\end{array}$ \\
\hline [33] & Moderate-severe & $\geq 18$ & 8 & $\begin{array}{l}\text { Fluticasone }+ \text { formoterol or } \\
\text { fluticasone monotherapy }\end{array}$ & $\begin{array}{l}\text { Morning pre-dose } \mathrm{FEV}_{1} \text { variation; } \\
\text { morning } \mathrm{FEV}_{1} \text { pre-dose vs } 2 \mathrm{~h} \\
\text { post-dose } \mathrm{FEV}_{1}\end{array}$ & Non inferiority \\
\hline$[34]$ & Mild-moderate/severe & $\geq 12$ & 12 & Fluticasone + formoterol & $\begin{array}{l}\text { Morning pre-dose } \mathrm{FEV}_{1} \text { vs } 2 \mathrm{~h} \\
\text { post-dose } \mathrm{FEV}_{1}\end{array}$ & Non inferiority \\
\hline [32] & Mild-moderate/severe & $\geq 18$ & 12 & Fluticasone/salmeterol & Morning pre-dose $\mathrm{FEV}_{1}$ variation & Non inferiority \\
\hline [50] & Moderate-severe & $\geq 12$ & 12 & Budesonide/formoterol & Morning pre-dose $\mathrm{FEV}_{1}$ variation & Non inferiority \\
\hline [51] & Moderate-severe & $\geq 12$ & 12 & Fluticasone or formoterol or placebo & $\begin{array}{l}\text { Morning pre-dose } \mathrm{FEV}_{1} \text { variation; } \\
\text { morning pre-dose } \mathrm{FEV}_{1} \text { vs } 2 \mathrm{~h} \\
\text { post-dose } \mathrm{FEV}_{1} \text {; treatment } \\
\text { discontinuation due to lack } \\
\text { of efficacy }\end{array}$ & Superiority \\
\hline$[52]$ & Mild-moderate/severe & $\geq 12$ & 6-12 months & Not applicable & Safety & Safe also at long term \\
\hline [53] & Mild-moderate & $\geq 12$ & 12 & Fluticasone or formoterol or placebo & $\begin{array}{l}\text { Morning pre-dose } \mathrm{FEV}_{1} \text { variation; } \\
\text { morning pre-dose } \mathrm{FEV}_{1} \text { vs } 2 \mathrm{~h} \\
\text { post-dose } \mathrm{FEV}_{1} \text {; treatment discon- } \\
\text { tinuation due to lack of efficacy }\end{array}$ & Superiority \\
\hline [54] & Mild-moderate & $\geq 12$ & 12 & Fluticasone or formoterol & $\begin{array}{l}\text { Morning pre-dose } \mathrm{FEV}_{1} \text { variation; } \\
\text { morning pre-dose } \mathrm{FEV}_{1} \text { vs } 2 \mathrm{~h} \\
\text { post-dose } \mathrm{FEV}_{1}\end{array}$ & Superiority \\
\hline [55] & Not indicated & $\geq 12$ & 12 & $\begin{array}{l}\text { Fluticasone (two different } \\
\text { formulations) }\end{array}$ & $\begin{array}{l}\text { Morning pre-dose } \mathrm{FEV}_{1} \text { vs } 2 \mathrm{~h} \\
\text { post-dose } \mathrm{FEV}_{1}\end{array}$ & Superiority \\
\hline
\end{tabular}

$\mathrm{FEV}_{1}$, forced expiratory volume in $1 \mathrm{~s}$.

period with the fluticasone propionate/formoterol combination. In particular, the results of this analysis revealed that the combined administration of fluticasone propionate/formoterol at every available dosage $(100 / 10 \mu \mathrm{g}$ b.i.d., $250 / 10 \mu$ b.i.d. and 500/20 $\mu$ g b.i.d.) showed a statistically significant superior efficacy to the administration of single components, as evaluated by $\mathrm{FEV}_{1}$ variations at baseline pre-dose and pre-dose at the end of the study $(p<0.001)[37,56]$. The results of the combined analysis showed that the fluticasone propionate/formoterol combination in a single dose inhaler is superior to the single components, also in terms of tolerability. Moreover, patients treated with the combined therapy experienced a lower rate of exacerbations than those treated with fluticasone propionate (odds ratio 0.75 ; IC 95\% 0.59-0.96) or with formoterol as monotherapy (odds ratio 0.49; IC 95\% 0.34-0.70) [37,57].

Furthermore, comparative studies performed on patients treated with fluticasone propionate/formoterol combination in a single dose inhaler versus the single components administered concurrently have shown the non-inferiority of the combination for: 12-hours serial $\mathrm{FEV}_{1}$ area under the curve (AUC), peak expiratory flow (PEF) in morning and evening pre-dose evaluations, asthma symptom scores, percentage of symptom-free days, quality of life (based on the Asthma Quality of Life Questionnaire, AQLQ), mean sleep disturbance scores, and number of uses of rescue medications. Additionally, the percentage of patients who were discontinued due to lack of efficacy of the therapy was lower in the group treated with the fluticasone/formoterol combination than in the group of patients who concurrently received the two medications at equivalent doses using two separate inhalers (3.9\% and 7.7\% respectively) $[37,57]$. The results of efficacy studies, conducted with the combined administration of fluticasone propionate/formoterol $(100 / 10 \mu \mathrm{g}$ b.i.d., $250 / 10 \mu$ b.i.d.) with fluticasone propionate/salmeterol (100/50 $\mu$ b.i.d., $250 / 50 \mu$ g b.i.d.) have shown the non-inferiority of the former in terms of $F V_{1}$ pre-dose baseline versus $F_{E V}$ pre-dose at week 12 of treatment $(p=0.007)$ and of $F_{E V}$ pre-dose baseline versus $F_{1} V_{1} 2 \mathrm{~h}$ post-dose at week 12 of treatment $(p=0.002)$, in terms of PEFR, sleep disturbance scores, rescue medication use and asthma exacerbations. These efficacy results were replicated when fluticasone propionate/ formoterol and budesonide/formoterol combined therapies were compared [50].

The results of clinical studies comparing fluticasone propionate/ formoterol combined therapy versus i) monotherapy with single components, ii) therapy with single components administered concurrently, iii) fluticasone propionate/salmeterol combined therapy, and iv) budesonide/formoterol combined therapy, showed superior efficacy for the fluticasone propionate/formoterol combination compared with monotherapy with single components. Moreover, fluticasone propionate/formoterol demonstrated non-inferiority to fluticasone propionate/salmeterol or budenoside/formoterol combinations, in terms of lung function and asthma control. However, the fluticasone/formoterol combination has a more rapid bronchodilator effect than the fluticasone propionate/salmeterol combined treatment, defined as the first postdose measurement with $\mathrm{FEV}_{1} \geq 12 \%$ of the corresponding pre-dose value $(\mathrm{p}=0.001)[32,37]$. Moreover, the fluticasone/formoterol combination is well tolerated at all considered doses [32-34,50-55], including in long-term treatments up to 12 months [52].

The clinical efficacy of an inhaler therapy is also based on the ability of the inhaler device to provide an adequate dose of medication to the lower respiratory tract. The drug particle size range is the main characteristic of the aerosol, determining rate, distribution and the deposition site of the medication inhaled by the airways. It has been demonstrated that the percentage of respirable fraction contained in the aerosol (defined as drug particles with the diameter range between 2 and $5 \mu \mathrm{m}$ ) correlates with the drug deposition in lung tissues [57,58]. The inhaler used for the administration of the fluticasone propionate/ formoterol combination ensures the distribution of an aerosol with a respirable fraction of $40 \%$ of the inhaled dose [59], which is consistent at different inspiratory flows, with a plume value of $168 \mathrm{~ms}$ [60]. These characteristics facilitate drug deposition throughout the airways.

The DIFFUSE study has extensively evaluated the particle size distribution of the aerosol delivered by the fluticasone/formoterol combination inhaler at the strength of $5 / 125 \mu \mathrm{g}$ in accordance with the European Pharmacopeia [59]. The mean $( \pm S D)$ Median Mass Aerodynamic Diameter (MMAD) and Geometric Standard Deviation (GSD) were respectively $3.52( \pm 1.59)$ for the LABA and $3.52( \pm 1.56)$ for the ICS at a flow of $28.3 \mathrm{lpm}$; the Fine Particle Fraction (FPF) of the labeled dose was, respectively, $39 \%$ and $41 \%$. Further in vivo studies should confirm these results, but they suggest a good and homogeneous lung drug distribution for both drugs. Interestingly, the fluticasone propionate/formoterol combination shows good consistency in proper drug delivery at different flow rates. In fact, the FPF at $60 \mathrm{lpm}$ showed percentages of $41 \%$ for the LABA and $44 \%$ for the ICS. This characteristic may be very important as fast inhalation is one of the most common 
errors with metered dose inhalers in clinical practice. Poor hand-lung coordination, another common misuse of inhaler technique, may be overcome, if necessary, using a valved holding chamber. The use of AeroChamber Plus, which, possibly, may also contribute to increase lung drug deposition, is suggested into the package leaflet of the fluticasone propionate/formoterol inhaler.

The same DIFFUSE study has compared the aerodynamics of fluticasone propionate/formoterol to that of two most commonly used LABA/ICS combination inhalers, such as salmeterol/fluticasone propionate Diskus and budesonide/formoterol Turbuhaler, respectively at the estimated equipotent strengths of 50/250 and 4/160 $\mu$ g. At $60 \mathrm{lpm}$, the optimal inhalation flow with both DPIs, the MMAD, GSD and FPF of labeled dose were, respectively, 4.0, 2.0 and 15\% for salmeterol and 3.7, 1.8 and $18 \%$ with fluticasone propionate. The MMAD, GSD and FPF of labeled dose were 2.5, 1.9 and 30\% with formoterol and 2.5, 1.9 and $35 \%$ with budesonide [59]. These results are substantially in accordance with other previously known, where the average MMAD, GSD and Fine Particle Dose of labeled dose were, respectively, 3.5, 1.5 and $18 \%$ for salmeterol and 3.6, 1.5 and 20\% with fluticasone propionate using the Diskus; and 3.3, 1.6 and 11\% with formoterol and 3.1, 1.6 and 13\% with budesonide using the Turbuhaler [61].

\section{Conclusion and discussion}

According to the recommendations of international guidelines, the aim of asthma management is reaching stable and optimal symptom control, improving patient quality of life, and minimizing the exacerbation rates, with the consequent reduction of direct and indirect health care costs. However, the results of many surveys among general practitioners, respiratory medicine specialists and patients reveal that a large percentage of asthma patients under treatment still have symptoms of not well controlled disease.

Combination treatment with a LABA in addition to ICS is the mainstay of the management of asthma, when the disease is not adequately controlled by low dose ICS alone. The administration of ICS and LABA in a single inhaler provides advantages in terms of pharmacology and compliance. Indeed, the two drugs in combination synergistically enhance the pharmacological effects of the two components. Moreover, the use of a single inhaler device improves patient adherence to therapy.

The results of clinical studies conducted on the fluticasone propionate/formoterol combination reveal that these two medications, when administered concurrently in a single inhaler, show efficacy and are well tolerated. Symptom control and consequently quality of life of asthma patients are improved.

The pharmacological characteristics of this combination fulfill the criteria established by the main international guidelines for asthma management, allowing the dosage flexibility required by step-up and step-down therapy.

The presence of formoterol in the combination with fluticasone propionate allows one or two inhalations per single administration, with a wider range of ICS and LABA dosages available to the patients. Moreover, the combination of fluticasone propionate and formoterol shares the most relevant characteristics of ICS and LABA respectively, recommended by physicians for effective asthma management.

To date, available data suggest that the combination of the antiinflammatory effects of fluticasone propionate and the rapid acting bronchodilator effects of formoterol provides a valid treatment option for asthma, from the point of view of both therapeutic efficacy and patient compliance.

The combination of fluticasone propionate ICS and formoterol LABA in a single inhaler for asthma treatment of adults (aged $\geq 12$ years) provides a valid therapeutic option in terms of efficacy, patient adherence to treatment and compliance to the recommendations of international guidelines.

\section{Learning points}

- The aim of asthma management is a stable and optimal symptom control, to minimize exacerbation rates and improving patient quality of life.

- In a large percentage of asthma patients disease is not controlled even if under treatment.

- The combination therapy with a LABA and ICS in a single inhaler allows one or two inhalations per single administration, providing pharmacological and compliance advantages.

- The combination of anti-inflammatory fluticasone and rapid-acting bronchodilator formoterol in a single inhaler shows efficacy and is well tolerated, fulfilling the International Guidelines Criteria.

\section{Disclosure}

All authors participated to an Editorial meeting hosted by Mundipharma S.r.l., Italy in order to discuss topics to be included in the paper.

The paper was completed independently with no funding. Editorial assistance for the publication of this manuscript was provided by HPS - Health Publishing \& Services S.r.l., Milan, Italy with a limited contribution by MundiPharma S.r.l. Italy

\section{Conflict of interest statement}

-A. Papi gave presentations at symposia sponsored by, received from or served on scientific advisory boards of Almirall, AstraZeneca, Boehringer Ingelheim, Chiesi, Dompè, GSK, Guidotti, Menarini, MSD, Mundipharma, Novartis, Pfizer, Takeda, TEVA, and Zambon.

-F. Blasi served as advisory board member or received lectures honoraria or research grants from AstraZeneca, Almirall, Bayer, Boehringer Ingelheim, Chiesi, Dompè, GSK, Guidotti-Malesci, Menarini, Mundipharma, Novartis, and Zambon.

-G.W. Canonica served as advisory board member or received lectures honoraria from AstraZeneca, Almirall, Boehringer Ingelheim, Chiesi, GSK, Guidotti-Malesci, Lallemand, Meda, Menarini, Mundipharma, Novartis, Recordati, and Uriach.

-M. Cazzola has received honoraria for speaking and consulting and/ or financial support for attending meetings from Almirall, AstraZeneca, Boehringer Ingelheim, Chiesi Farmaceutici, Dey, GlaxoSmithKline, Lallemand, Menarini Farmaceutici, Mundipharma, Novartis, Pfizer, Sigma Tau, and Takeda.

$-S$. Centanni reports having received lecture fees from: Pfizer, Novartis, GSK, Mundipharma, Angelini, Almirall, Boehringer Ingelheim, and Chiesi Farmaceutici.

-M.P. Foschino received lecture fees from Mundhipharma, GuidottiMalesci, Almirall, and Astra Zeneca

-A.S. Melani has served as an advisory board member, has been reimbursed for speaker honoraria, and has received fees as a consultant from Chiesi, Menarini Farmaceutici, Novartis, Mundipharma, GSK, Sanofi-Aventis, Almirall and Artsana.

-P.L. Paggiaro received lecture fees from: AstraZeneca, Chiesi, Menarini, MSD, Novartis, and Takeda. Lecture fees: AstraZeneca, Boehringer Ingelheim, Chiesi, Guidotti-Malesci, GSK, Menarini, MSD, Mundipharma, Novartis, Takeda, Valeas, and Zambon. Consultancies: AstraZeneca, Boehringer Ingelheim, Chiesi, Guidotti-Malesci, MSD, Mundipharma, and Novartis.

-F. Ricciardolo received grants from Boehringer (grant no. DE811138149); Lecture fees from Mundipharma, Almirall, Novartis, Chiesi, Takeda, Abbott and Astra; and Consultancies from Mundipharma, Novartis, Chiesi, and Guidotti-Malesci.

-A. Rossi received lecture fee from Astra/Zeneca, Boehringer Ingelheim, Chiesi, GlaxoSmithKline, and Novartis. 
$-\mathrm{N}$. Scichilone received lecture fees from Mundipharma, Chiesi Novartis, Chiesi, Astra Zeneca, and GSK and consultancies from Mundipharma, Astra Zeneca, Chiesi, Boehringer, and Dompè.

\section{References}

[1] Bousquet J, Mantzouranis E, Cruz AA, et al. Uniform definition of asthma severity, control, and exacerbations: document presented for the World Health Organization Consultation on Severe Asthma. J Allergy Clin Immunol 2010;126:926-38.

[2] Masoli M, Fabian D, Holt S, Beasley R. The global burden of asthma: executive summary of the GINA Dissemination Committee report. Allergy 2004;59:469-78.

[3] Juniper EF. Quality of life in adults and children with asthma and rhinitis. Allergy 1997;52:971-7.

[4] Anderson HR. Prevalence of asthma. BMJ 2005;330:1037-8.

[5] Demoly P, Annunziata K, Gubba E, Adamek L. Repeated cross-sectional survey of patient-reported asthma control in Europe in the past 5 years. Eur Respir Rev 2012;21:66-74.

[6] Papi A. A new combination therapy for asthma: bridging the gap between effectiveness in trials and clinical practice? Respir Med 2012;106(Suppl. 1):S1-3.

[7] Partridge MR, van der Molen T, Myrseth SE, Busse WW. Attitudes and actions of asthma patients on regular maintenance therapy: the INSPIRE study. BMC Pulm Med 2006;6:13.

[8] Rees J. Asthma control in adults. BMJ 2006;332:767-71

[9] Rabe KF, Vermeire PA, Soriano JB, Maier WC. Clinical management of asthma in 1999: the Asthma Insights and Reality in Europe (AIRE) study. Eur Respir J 2000;16:802-7.

[10] Demoly P, Gueron B, Annunziata K, Adamek L, Walters RD. Update on asthma control in five European countries: results of a 2008 survey. Eur Respir Rev 2010;19:150-7.

[11] Demoly P, Paggiaro P, Plaza V, Bolge SC, Kannan H, Sohier B, et al. Prevalence of asthma control among adults in France, Germany, Italy, Spain and the UK. Eur Respir Rev 2009;18:105-12.

[12] Thomas M, McKinley RK, Freeman E, Foy C, Prodger P, Price D. Breathing retraining for dysfunctional breathing in asthma: a randomised controlled trial. Thorax 2003;58:110-5.

[13] Corsico AG, Cazzoletti L, de Marco R, et al. Factors affecting adherence to asthma treatment in an international cohort of young and middle-aged adults. Respir Med 2007;101:1363-7.

[14] Papi A, Haughney J, Virchow JC, Roche N, Palkonen S, Price D. Inhaler devices for asthma: a call for action in a neglected field. Eur Respir J 2011;37:982-5.

[15] Melani AS, Bonavia M, Cilenti V, et al. Inhaler mishandling remains common in real life and is associated with reduced disease control. Respir Med 2011;105:930-8.

[16] Dolovich MB, Ahrens RC, Hess DR, et al. Device selection and outcomes of aerosol therapy: evidence-based guidelines: American College of Chest Physicians/ American College of Asthma, Allergy, and Immunology. Chest 2005;127:335-71.

[17] Anderson P. Patient preference for and satisfaction with inhaler devices. Eur Respir Rev 2005;14:109-16.

[18] Braido F, Baiardini I, Stagi E, Piroddi MG, Balestracci S, Canonica GW. Unsatisfactory asthma control: astonishing evidence from general practitioners and respiratory medicine specialists. J Investig Allergol Clin Immunol 2010;20:9-12.

[19] Canonica GW, Baena-Cagnani CE, Blaiss MS, Dahl R, Kaliner MA, Valovirta EJ. Unmet needs in asthma: Global Asthma Physician and Patient (GAPP) Survey: global adult findings. Allergy 2007;62:668-74.

[20] Kupczyk M, Wenzel S. U.S. and European severe asthma cohorts: what can they teach us about severe asthma? J Intern Med 2012;272:121-32.

[21] Greening AP, Ind PW, Northfield M, Shaw G. Added salmeterol versus higher-dose corticosteroid in asthma patients with symptoms on existing inhaled corticosteroid. Allen \& Hanburys Limited UK Study Group. Lancet 1994;344:219-24.

[22] Marceau C, Lemiere C, Berbiche D, Perreault S, Blais L. Persistence, adherence, and effectiveness of combination therapy among adult patients with asthma. J Allergy Clin Immunol 2006;118:574-81.

[23] Nelson HS, Chapman KR, Pyke SD, Johnson M, Pritchard JN. Enhanced synergy between fluticasone propionate and salmeterol inhaled from a single inhaler versus separate inhalers. J Allergy Clin Immunol 2003;112:29-36.

[24] Stempel DA, Stoloff SW, Carranza Rosenzweig JR, Stanford RH, Ryskina KL, Legorreta AP. Adherence to asthma controller medication regimens. Respir Med 2005;99:1263-7.

[25] Stoloff SW, Stempel DA, Meyer J, Stanford RH, Carranza Rosenzweig JR. Improved refill persistence with fluticasone propionate and salmeterol in a single inhaler compared with other controller therapies. J Allergy Clin Immunol 2004;113:245-51.

[26] Bateman ED, Boushey HA, Bousquet J, et al. Can guideline-defined asthma control be achieved? The Gaining Optimal Asthma ControL study. Am J Respir Crit Care Med 2004;170:836-44

[27] O'Byrne PM, Barnes PJ, Rodriguez-Roisin R, et al. Low dose inhaled budesonide and formoterol in mild persistent asthma: the OPTIMA randomized trial. Am J Respir Crit Care Med 2001;164:1392-7.

[28] Pauwels RA, Lofdahl CG, Postma DS, et al. Effect of inhaled formoterol and budesonide on exacerbations of asthma. Formoterol and Corticosteroids Establishing Therapy (FACET) International Study Group. N Engl J Med 1997;337:1405-11.

[29] Bousquet J, Winchester C, Papi A, et al. Inhaled corticosteroid/long-acting beta(2)agonist combination therapy for asthma: attitudes of specialists in Europe. Int Arch Allergy Immunol 2012;157:303-10.

[30] British Thoracic Society and Scottish Intercollegiate Guidelines Network. British Guideline on the Management of Asthma. Revised Jan 2012 http://www.sign.ac. uk; 2008.
[31] Global Initiative for Asthma GINA. Global strategy for asthma management and prevention. http://www.ginaasthma.org.

[32] Bodzenta-Lukaszyk A, Dymek A, McAulay K, Mansikka H. Fluticasone/formoterol combination therapy is as effective as fluticasone/salmeterol in the treatment of asthma, but has a more rapid onset of action: an open-label, randomized study. BMC Pulm Med 2011;11:28.

[33] Bodzenta-Lukaszyk A, Pulka G, Dymek A, et al. Efficacy and safety of fluticasone and formoterol in a single pressurized metered dose inhaler. Respir Med 2011:105:674-82.

[34] Bodzenta-Lukaszyk A, van Noord J, Schroder-Babo W, et al. Efficacy and safety profile of fluticasone/formoterol combination therapy compared to its individual components administered concurrently in asthma: a randomised controlled trial. Curr Med Res Opin 2013;29:579-88.

[35] Tamm M, Richards MDH, Beghe B, Fabbri L. Inhaled corticosteroid and long-acting beta $_{2}$-agonist pharmacological profiles: effective asthma therapy in practice. Respir Med 2012;106(Suppl. 1):S9-S19.

[36] Barnes PJ. Scientific rationale for using a single inhaler for asthma control. Eur Respir J 2007;29:587-95

[37] McKeage K. Fluticasone propionate/formoterol fumarate: a review of its use in persistent asthma. Drugs 2013;73:195-206.

[38] Derendorf H, Nave R, Drollmann A, Cerasoli F, Wurst W. Relevance of pharmacokinetics and pharmacodynamics of inhaled corticosteroids to asthma. Eur Respir J 2006;28:1042-50.

[39] Hubner M, Hochhaus G, Derendorf H. Comparative pharmacology, bioavailability pharmacokinetics, and pharmacodynamics of inhaled glucocorticosteroids. Immunol Allergy Clin N Am 2005;25:469-88.

[40] Rohatagi S, Appajosyula S, Derendorf H, et al. Risk-benefit value of inhaled glucocorticoids: a pharmacokinetic/pharmacodynamic perspective. J Clin Pharmacol 2004; 44:37-47.

[41] Cazzola M, Page CP, Rogliani P, Matera MG. Beta2-agonist therapy in lung disease. Am J Respir Crit Care Med 2013;187:690-6.

[42] Palmqvist M, Persson G, Lazer L, Rosenborg J, Larsson P, Lotvall J. Inhaled drypowder formoterol and salmeterol in asthmatic patients: onset of action, duration of effect and potency. Eur Respir J 1997;10:2484-9.

[43] Lotvall J. The long and short of beta2-agonists. Pulm Pharmacol Ther 2002; 15:497-501.

[44] Charlton SJ. Agonist efficacy and receptor desensitization: from partial truths to a fuller picture. Br J Pharmacol 2009;158:165-8.

[45] McDonnell J, Latif ML, Rees ES, Bevan NJ, Hill SJ. Influence of receptor number on the stimulation by salmeterol of gene transcription in CHO-K1 cells transfected with the human beta2-adrenoceptor. Br J Pharmacol 1998;125:717-26.

[46] Hanania NA, Sharafkhaneh A, Barber R, Dickey BF. Beta-agonist intrinsic efficacy: measurement and clinical significance. Am J Respir Crit Care Med 2002;165:1353-8.

[47] Scola AM, Chong LK, Chess-Williams R, Peachell PT. Influence of agonist intrinsic activity on the desensitisation of beta2-adrenoceptor-mediated responses in mast cells. Br J Pharmacol 2004;143:71-80.

[48] Goral V, Jin Y, Sun H, Ferrie AM, Wu Q, Fang Y. Agonist-directed desensitization of the beta2-adrenergic receptor. PLoS One 2011;6:e19282.

[49] Dissanayake S, Grothe B, Kaiser K. Fluticasone/formoterol: a new single-aerosol combination therapy for patients with asthma. Respir Med 2012;106(Suppl. 1):S20-8.

[50] Bodzenta-Lukaszyk A, Buhl R, Balint B, Lomax M, Spooner K, Dissanayake S Fluticasone/formoterol combination therapy versus budesonide/formoterol for the treatment of asthma: a randomized, controlled, non-inferiority trial of efficacy and safety. J Asthma 2012;49:1060-70.

[51] Corren J, Mansfield LE, Pertseva T, Blahzko V, Kaiser K. Efficacy and safety of fluticasone/formoterol combination therapy in patients with moderate-to-severe asthma. Respir Med 2013;107:180-95.

[52] Mansur AH, Kaiser K. Long-term safety and efficacy of fluticasone/formoterol combination therapy in asthma. J Aerosol Med Pulm Drug Deliv 2013;26:190-9.

[53] Nathan RA, D'Urzo A, Blazhko V, Kaiser K. Safety and efficacy of fluticasone/ formoterol combination therapy in adolescent and adult patients with mild-tomoderate asthma: a randomised controlled trial. BMC Pulm Med 2012;12:67.

[54] Pearlman DS, LaForce CF, Kaiser K. Fluticasone/formoterol combination therapy compared with monotherapy in adolescent and adult patients with mild to moderate asthma. Clin Ther 2013;35:950-66.

[55] Pertseva T, Dissanayake S, Kaiser K. Superiority of fluticasone propionate/formotero fumarate versus fluticasone propionate alone in patients with moderate-to-severe asthma: a randomised controlled trial. Curr Med Res Opin 2013;29:1357-69.

[56] Price D, Papi A, Kaiser K. Patients with asthma show greater improvements in lung function after combination therapy with fluticasone propionate/formoterol fumarate than with its individual components administered alone (abs 277). 6th International Primary Care and Respiratory Group World Conference, Edinburgh 25-28 Apr 2012; 2012.

[57] Dissanayake S, Lemax M, Kaiser T, et al. Asthma exacerbations with fluticasone propionate/formoterol fumarate combination therapy versus its individual components (abs. P2096). European Respiratory Society Annual Congress, Wien 1-5 Sep 2012; 2012

[58] Newman SP, Chan HK. In vitro/in vivo comparisons in pulmonary drug delivery. J Aerosol Med Pulm Drug Deliv 2008;21:77-84.

[59] Johal M, Howald M, Fischer M, Marshall J, Venthoye G. Fine particle profile of fluticasone propionate/formoterol fumarate versus other combination products: the DIFFUSE study. Comb Prod Ther 2013;3:39-51.

[60] Johal B, Murphy S, Marshall J. Plume characteristics of fluticasone propionate/formoterol pMDI compared with fluticasone propionate/salmeterol pMDI (abs P4132). European Respiratory Society Annual Congress, Barcelona 7-11 Sep 2013; 2013.

[61] Tarsin WY, Pearson SB, Assi KH, Chrystyn H. Emitted dose estimates from Seretide Diskus and Symbicort Turbuhaler following inhalation by severe asthmatics. Int J Pharm 2006;316:131-7. 